\title{
The 3 vs 1 game build-up effectiveness examination in physical and technical tests of 11 -year-old football players
}

\author{
Janos Tóth jr. ${ }^{1}$, David Zalai ${ }^{2}$, Janos Tóth ${ }^{1}$, Pál Hamar ${ }^{3}$ \\ ${ }^{1}$ Semmelweis University, Faculty of Physical Education and Sport Sciences, Department of Sport Games; ${ }^{2}$ Semmelweis \\ University, Faculty of Physical Education and Sport Sciences, Ph.D. Student; ${ }^{3}$ Semmelweis University, Faculty of Physical \\ Education and Sport Sciences, Department of Gymnastics, Rhytmic Gymnastics, Dance and Aerobics
}

\section{Summary}

Study aim: The aim of this study is to prove that young players who have been coached with the main focus on technical ability and player interaction, perform better when tested on physical and technical attributes.

Material and methods: We examined 2 separate groups made up of 15 players each. After thorough analysis, the experimental group practiced playing forms to building up 3 vs 1 games weekly for one year. The control group did not follow this training pattern.

Results: Over the course of the year there was a constant development in all aspects of the examination. Furthermore, both physical and technical attributes were significantly better. The same cannot be concluded from the analysis of the control group, in which the performance level even dropped in some aspects of the examination.

Conclusion: The results show that players practicing the playing forms on a weekly basis performed better in physical and technical tests. In addition, subjective experience has also underlined the effect of the method.

\section{Keywords: soccer, age-group training, exercises}

\section{Introduction}

Euro 2012 was a huge success and demonstrated how much people love the game. The children in the age group we analyzed in this study also show their dedication towards soccer [13], wearing star-player shirts and collecting soccer cards . The most children in this group want to be active participant $\mathrm{s}$ in football, and therefore are involved in soccer coaching and lessons.

Coaches have great responsibility in controlling the fanatism of children [8]. Training sessions have to be structured so that children enjoy them and have the feeling of success, boosting their confidence, which can be a very important step during the development of a player [2,7]. Furthermore, this is an important period in players' cognitive development $[4,11]$. However, it is important that parallel to football the children perform well in school, although harmonizing football or a professional sports career - with studying is never easy [12].
An important element of youth coaching is 3 vs 1 with which the players can practice both tactical and technical elements of the game. With the variation of time, space and dynamics, 3 vs 1 can also be useful in condition training [1,9]. We do not start off with the 3 vs 1 game but first focus on the relation between 2 and 3 players. These must be just as enjoyable for the young players, as children lose focus and get bored if the training exercise does not include a fun factor. It is important to note that prevention is very important, as already at this age more non-contact injuries occur in soccer then in any other contact sport [6].

Our hypothesis is that the experimental group practicing 3 vs 1 - will have significantly better results in both technical and physical tests.

\section{Material and Methods}

We made our observations in a test and control group organized within the youth education of our trainer's work.

Author's address Janos Tóth jr., Semmelweis University, Faculty of Physical Education and Sport Science 1123 Alkotas street 44 , Budapest, Hungary tothj@tf.hu 
Table 1. Test groups

\begin{tabular}{lcc}
\hline Groups & Birth Year & Participants number \\
\hline Control group & 1997 & $\mathrm{~N}=15$ players \\
Intervention group & 1997 & $\mathrm{~N}=15$ players \\
\hline
\end{tabular}

The first test was completed in August 2008 and was followed by the experimental group working with a training program based on the build-up and execution of 3 vs 1 games.

In August 2009 the second test was completed involving the 2 groups. The examination was made up of 3 physical and 3 technical parts. These and similar tests are also applied in other studies $[4,11]$. We used Statistic 11 with a 1 (Wilcox) and 2 (Mann-Whitney) sample $t$-test.

The physical tests were as follows:

Long jump from a static position

All players had 2 attempts of which the better result was taken into account. The exercise shows the explosive strength, the scaler quality value, and the jumping ability of the lower limbs. tion

Fifteen-meter sprint from a crossed legged sitting posi-

Again, all players have 2 attempts of which the more successful is taken into account. The speed of the players is measured is this exercise. (It can be measured in several different ways for football players.)

Twenty-meter shuttle run test

Twenty meters to be covered constantly following a signal. The exercise tests the players' endurance. Every player completes the task once.

The technical tests were as follows:

\section{Slalom dribbling}

This sport-specific exercise is one of the basic technical exercises even at school level. The player starts on the whistle and dribbles the ball in and out of cones using both feet. Five cones are set 2 meters apart from each other. The player dribbles up to the last cone where he/she turns and completes the task by dribbling back through the cones. The timer is stopped when the player passes the starting line. The exercise shows the quality of dribbling skills, including the ability to judge space and distance.

\section{Accuracy test}

The starting position is 7 meters from the middle of the goal. The player completes the exercise by aiming and shooting at the small boxes next to the posts. The players use the inside of the foot taking 10 shots each with the right and left foot. The player chooses which small box he/she is aiming at. This exercise, which is performed only once, is a good reference to the passing and shooting accuracy of a player.

\section{Keepie up}

The ball can be in the hand or on the ground when starting this exercise. The players have 1 minute to perform as many keepie-ups as possible. The players can use all body parts, just not the arms. The first touch counts towards the score and in case the ball hits the ground the player can start the exercise again. This exercise is to test the players' sense of space and touch of the ball.

The thematical build-up of the 3 vs 1 playing form consisted of the following drills:

\section{Two players working together}

The two players pass the ball to each other constantly. After passing the ball, the player runs to a free cone, and then runs back to the middle.

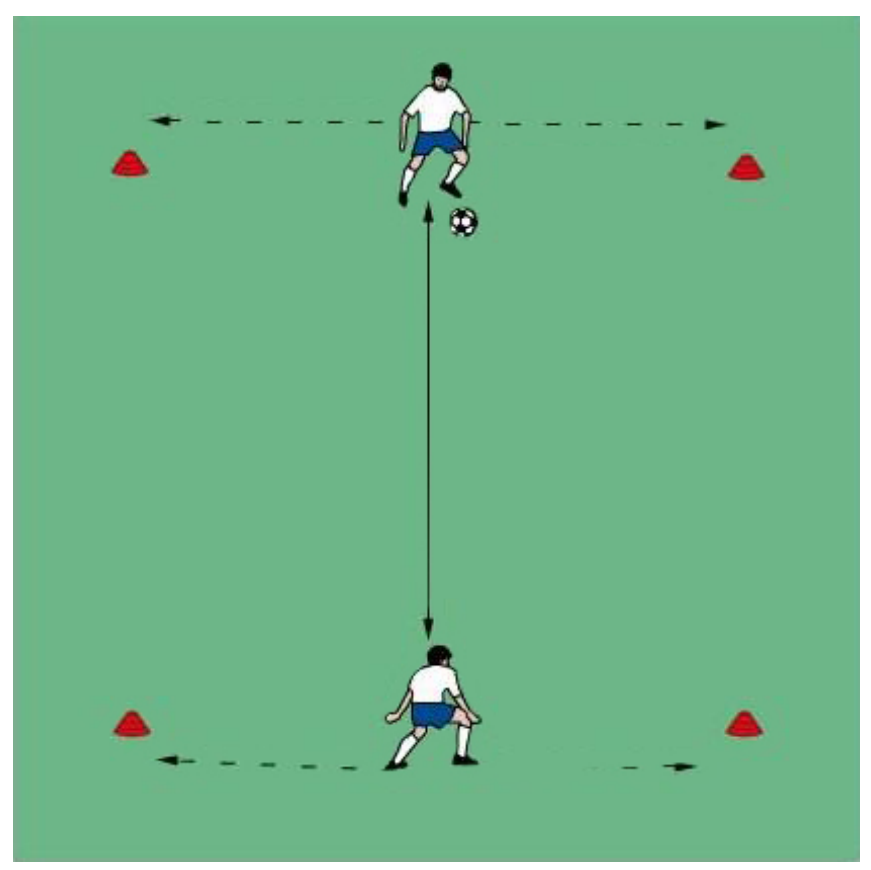

Figure 1. Exercise of two players working together

\section{Three players working together I.}

Three players working together with the player in the middle always supporting the players on the wings. (1.) After the player on the wing (A) passes deep to the player on the other end (B) (2.) the player in the middle immediately steps towards (B) and after receiving the ball lays it down to (B) again (3.) who passes to it the other end. The sequence continues following the same pattern. 


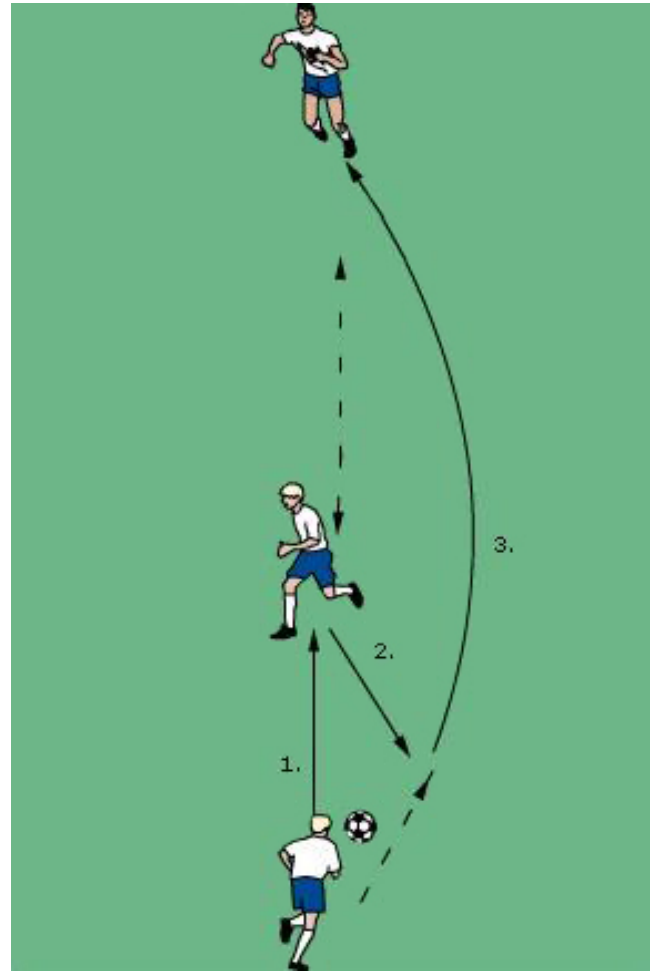

Figure 2. Exercise of three players working together I

\section{Three players working together II.}

Three players working together with the player in the middle always supporting the players on the wings. (1.) After the player on the wing (A) passes deep to the player on the other end (B) (2.) the player in the middle immediately steps towards (B) and after receiving the ball lays it down to (B) again (3.) who passes it to

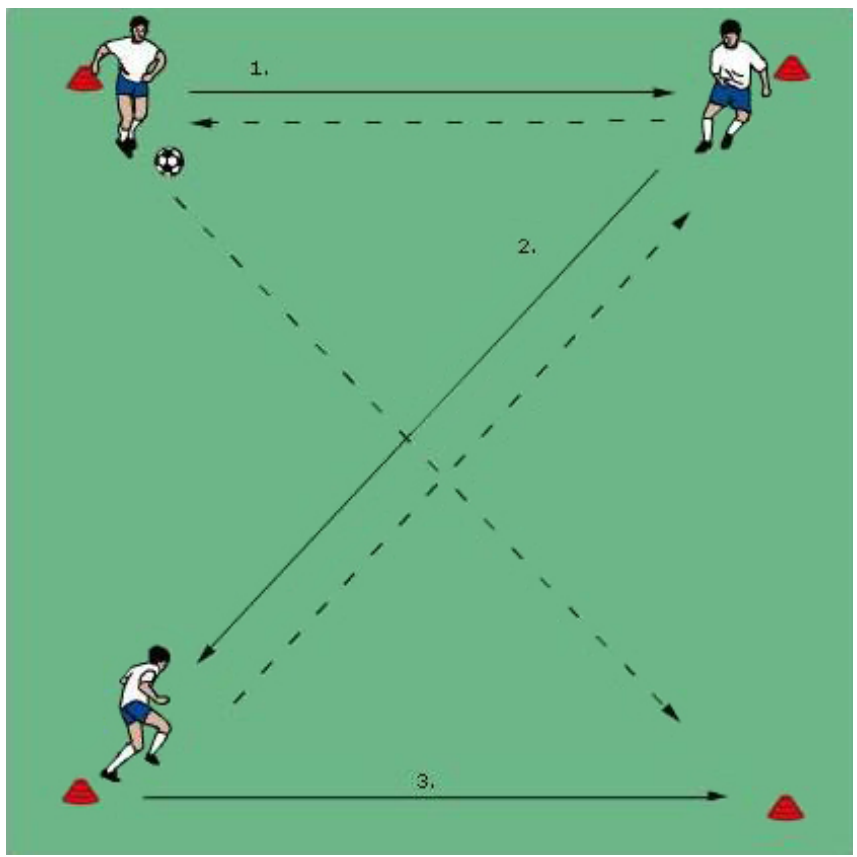

Figure 3. Exercise of three players working together II the other end. The sequence continues following the same pattern.

\section{Three players working together III:}

For this exercise the players again work in a square. Player (A) passes to (B), while (C) sprints towards (B) to support, receives the ball and plays it back to (B).

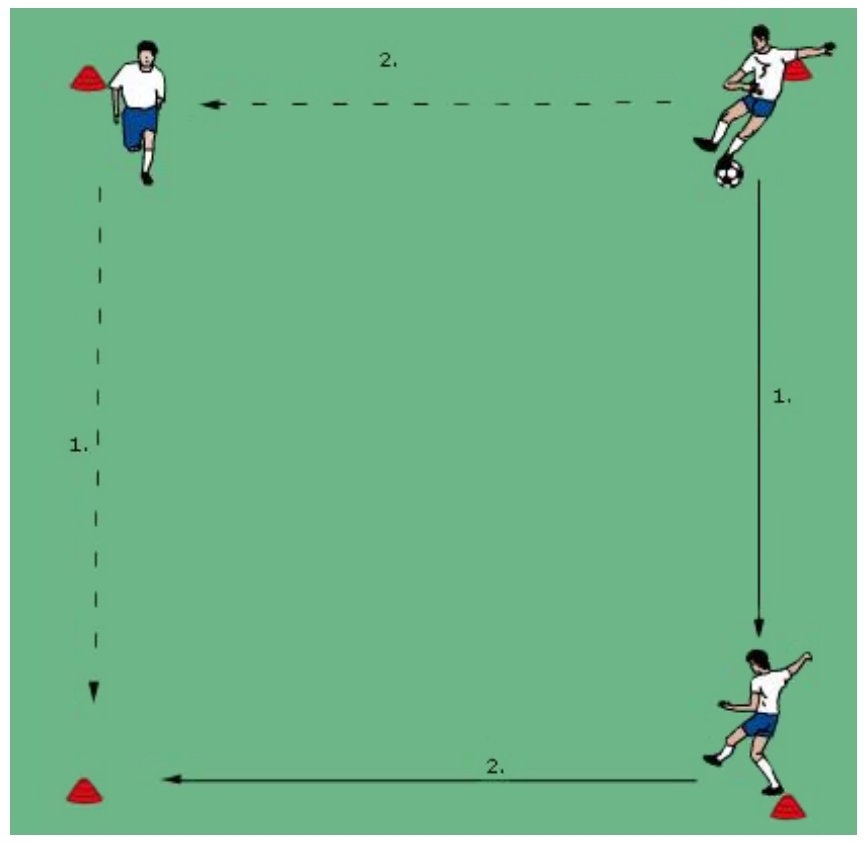

Figure 4. Exercise of three players working together III

\section{3 vs 1}

The peak of the process is the 3 vs 1 game, during which 3 players try to keep possession as long as possible. The aim is to fill the empty spaces and always provide 2 options for the player on the ball.

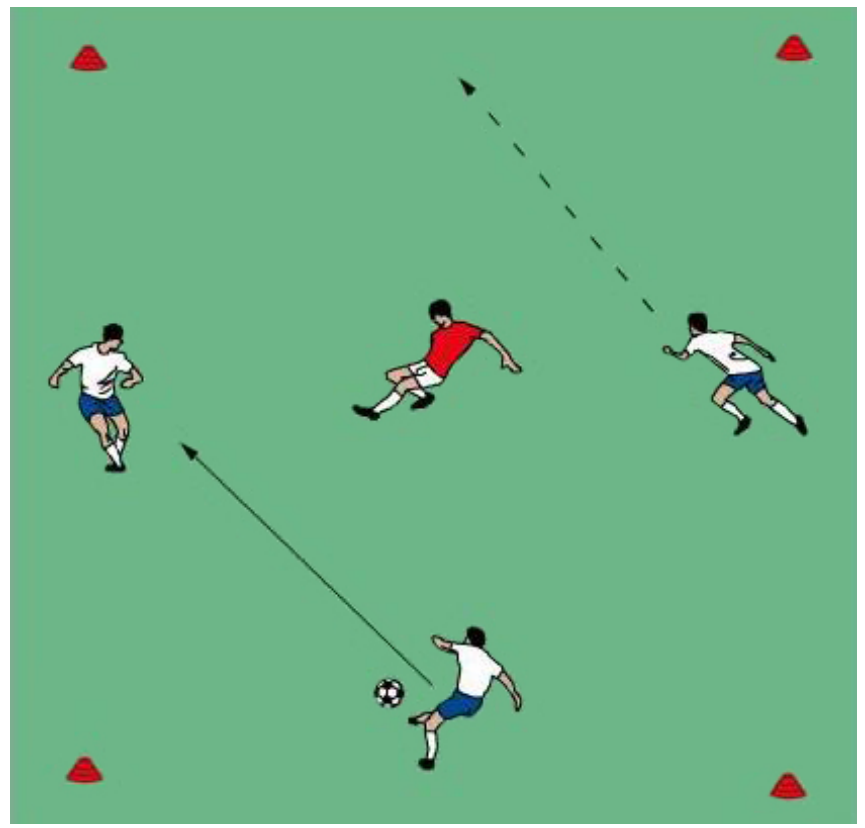

Figure 5. 3 vs 1 exercise 


\section{Results and discussion}

The players (children) liked the exercises, as they were very entertaining due to the game-like approach. Players can develop their technical and technical skills while performing fun exercises without realizing the hard work they are putting in.

Looking at the accuracy test results, players performed much better using the right foot, which is clearly due to the fact that there are more right-footed players among the children examined. The results show that there was a significant improvement in all the players. However, past studies have proved that development also comes from growth [5]. Nevertheless, in this case the improvement of the experimental group was remarkable.

Looking at the results we can conclude that there was improvement in all aspects of the tests. We measured an improvement of $18.6 \mathrm{~cm}$ in the long jump test. The 15-meter sprint was completed, on average, 0.2 seconds faster. The shuttle running performance grew by a staggering 15.26 runs.

As for the technical tests, players performed 2.16 seconds better at the slalom dribbling exercise. The significance of statistical calculations was accepted at $\mathrm{p}<0.05$.

Furthermore, there was also improvement in both technical and tactical aspects from an objective and subjective point of view. When testing the players in March, the number of completed passes was from 3 to 5. By December it was 6 to 8 . Constant practice, and growing tactical and technical awareness have resulted in a higher quality of execution of the exercises.

The control group, which did not completed the " 3 vs 1 program", reached a $4.4 \mathrm{~cm}$ improvement in the long jump test compared to $18.6 \mathrm{~cm}$ in the experimental group. Improvement in the slalom dribbling exercise was more significant, although the control group

Table 2. Intervention group results

\begin{tabular}{|c|c|c|c|c|c|c|c|}
\hline \multicolumn{8}{|c|}{2008} \\
\hline & $\begin{array}{l}\text { Standing } \\
\text { long jump }\end{array}$ & $15 \mathrm{~m}$ tailor seat & $20 \mathrm{~m}$ shuttle run & $\begin{array}{c}\text { Slalom ball } \\
\text { control }\end{array}$ & \multicolumn{2}{|c|}{ Goal shooting (n) } & Ball juggling \\
\hline & $(\mathrm{cm})$ & $(\mathrm{sec})$ & (distance) & $(\mathrm{sec})$ & $\mathrm{L}$ & $\mathrm{R}$ & (n) \\
\hline Rate ratio & 12.376 & 0.299 & 11.438 & 1.79 & 1.454 & 0.961 & 11.628 \\
\hline Avarage & 149.8 & 4.19 & 52.6 & 16.48 & 2.4 & 2.27 & 47.07 \\
\hline \multicolumn{8}{|c|}{2009} \\
\hline & $\begin{array}{l}\text { Standing } \\
\text { long lump }\end{array}$ & $15 \mathrm{~m}$ tailor seat & $20 \mathrm{~m}$ shuttle run & $\begin{array}{c}\text { Slalom ball } \\
\text { control }\end{array}$ & \multicolumn{2}{|c|}{ Goal shooting (n) } & Ball juggling \\
\hline & $(\mathrm{cm})$ & $(\mathrm{sec})$ & (distance) & $(\mathrm{sec})$ & $\mathrm{L}$ & $\mathrm{R}$ & (n) \\
\hline Rate ratio & 13.116 & 0.275 & 10.322 & 1.069 & 1.438 & 0.743 & 16.765 \\
\hline Avarage & 154.2 & 4.16 & 56.53 & 12.87 & 3.07 & 2.53 & 46.93 \\
\hline
\end{tabular}

Table 3. Control group results

\begin{tabular}{|c|c|c|c|c|c|c|c|}
\hline \multicolumn{8}{|c|}{2008} \\
\hline & $\begin{array}{l}\text { Standing } \\
\text { long jump }\end{array}$ & & & $\begin{array}{l}\text { Slalom ball } \\
\text { control }\end{array}$ & \multicolumn{2}{|c|}{ Goal shooting $(\mathrm{n})$} & \\
\hline & $(\mathrm{cm})$ & $(\mathrm{sec})$ & (distance) & $(\mathrm{sec})$ & $\mathrm{L}$ & $\mathrm{R}$ & (n) \\
\hline Rate ratio & 12.376 & 0.299 & 11.438 & 1.79 & 1.454 & 0.961 & 11.628 \\
\hline Avarage & 149.8 & 4.19 & 52.6 & 16.48 & 2.4 & 2.27 & 47.07 \\
\hline \multicolumn{8}{|c|}{2009} \\
\hline & $\begin{array}{l}\text { Standing } \\
\text { long jump }\end{array}$ & $15 \mathrm{~m}$ tailor seat & $20 \mathrm{~m}$ shuttle run & $\begin{array}{l}\text { Slalom ball } \\
\text { control }\end{array}$ & \multicolumn{2}{|c|}{ Goal shooting (n) } & Ball juggling \\
\hline & $(\mathrm{cm})$ & $(\mathrm{sec})$ & (distance) & $(\mathrm{sec})$ & $\mathrm{L}$ & $\mathrm{R}$ & (n) \\
\hline Rate ratio & 13.116 & 0.275 & 10.322 & 1.069 & 1.438 & 0.743 & 16.765 \\
\hline Avarage & 154.2 & 4.16 & 56.53 & 12.87 & 3.07 & 2.53 & 46.93 \\
\hline
\end{tabular}


started with an almost 3-second deficit compared to the experimental group. Regarding the accuracy test, improvement was lower than in the experimental group. The shuttle run results grew from 52.6 runs to 56.53 . The keepie-up results were worse than in the first test, although the results within the group have also differed significantly. The average of the control group is worse then in the experimental group.

We can draw the conclusion that our hypothesis was correct and that the experimental group produced better results in the tests. The exercises resulted in better physical and technical abilities, explosive strength, agility and speed. Improved ball control meant that the players could execute the exercises with higher quality despite their growing running speed, while maintaining a controlled body structure!

By using these exercises, teachers and coaches can participate in developing players using playing forms, thus making sport more enjoyable for young players.

\section{References}

1. Aguiar B., Lago M., Maças G., Sampaio J.V. (2012) A Review on the Effects of Soccer Small-Sided Games. J. Hum. Kinet., 33: 103-113.

2. Bakkera A., Oerlemansa W., Demeroutib E., Slotc B., Alid D. (2011) Flow and performance: A study among talented Dutch soccer players. Psych. Sport Exerc., 12: 442-450.

3. Bullock W., Panchuk D., Broatch J., Christian R., Stepto N.K. (2012) An integrative test of agility, speed and skill in soccer: Effects of exercise. J. Sci. Med. Sport, 15: 431-436.

4. Dardouri W., Amin Selmi M., Haj Sassi R., Gharbi Z., Rebhi A., Moalla W. (2013) Reliability and discriminative power of soccer-specific field tests and skill index in young soccer players. Science and Sports. http://dx.doi. org/10.1016/j.scispo.2013.06.004 (Article in press).
5. Huijgen B., Elferink-Gemser M., Post W., Visscher C. (2010) Development of dribbling in talented youth soccer players aged 12-19 years. J. Sports Sci., 28: 689-698.

6. Chris G.K., Andrew J.M.G. (2010) Injuries in Youth Soccer. Pediatrics, 125: 410-414.

7. Holt J.E., Kinchin G., Clarke G. (2012) Effects of peerassessed feedback, goal setting and a group contingency on performance and learning by 10-12-year-old academy soccer players. Phys. Edu. Sport Pedagog., 17: 231-250.

8. Taylor I., Bruner M. (2012) The social environment and developmental experiences in elite youth soccer. Psychol. Sport Exerc., 13: 390-396.

9. Köklü Y. (2012) A Comparison Of Physiological Responses To Various Intermittent And Continuous Small-Sided Games In Young Soccer Players. J. Hum. Kinet., 31: 89-96.

10. Miranda R.E.E.P.C., Antunes H.K.M., Pauli J.R., Puggina E.F., da Silva A.S.R. (2013) Effects of 10-week soccer training program on anthropometric, psychological, technical skills and specific performance parameters in youth soccer players. Sci. Sports, 28: 81-87.

11. Munroe-Chandler K., Hall C., Fishburne G., Murphy L., Hall N. (2012) Effects of a cognitive specific imagery intervention on the soccer skill performance of young athletes: Age group comparisons. Psychol. Sport Exerc., 13: 324-331.

12. Mette K.C., Jan K.S. (2009) Sport or school? Dreams and dilemmas for talented young Danish football players. Eur. Phys. Edu. Rev., 15: 115-133.

13. McCarthy P.J., Jones M.V., Clark-Carter D. (2008) Understanding enjoyment in youth sport: A developmental perspective. Psychol. Sport Exerc., 9: 142-156.

\section{Received 05.12.2012 \\ Accepted 03.12.2013}

(C) University of Physical Education, Warsaw, Poland 